\title{
Analisis Teknik Dasar Pemain Sepak Bola Tabulasi PSTS Padang
}

\author{
Irfan Irawan ${ }^{1}$, Heru Syarli Lesmana ${ }^{2}$, Kibadra $^{2}$ \\ ${ }^{123}$ Fakultas Ilmu Keolahragaan, Universitas Negeri Padang, Indonesia.
}

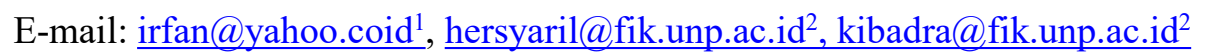

\begin{abstract}
Abstrak
Analisis Teknik Dasar Pemain Sepak Bola Tabulasi PSTS PadangTujuan dari penelitian ini adalah untuk menentukan tingkat kemampuan teknis untuk menembak pemain Tabing PSTS sehingga hasil pelatihan lebih spesifik untuk penguasaan teknik menembak. Penelitian ini dilakukan di Tabing PSTS.

Populasi dalam penelitian ini dilakukan pada 123 pemain Tabing PSTS, sedangkan teknik pengambilan sampel dilakukan dengan purposive sampling, yaitu 21 orang sebanyak 25 orang, pengumpulan data langsung di bidang Tabing PSTS dan dalam implementasinya dibantu oleh tiga orang penilaian yang memiliki lisensi pelatihan.

Analisis data penelitian ini menggunakan teknik persentase (distribusi frekuensi) yaitu. Dari analisis data U-21 diperoleh tahap awal, yaitu rata-rata $=9,2(76,67 \%)$ dikategorikan cukup, fase implementasi adalah rata-rata $=17,24(71,83 \%)$ dikategorikan cukup, dan fase akhir adalah rata-rata $=$ $5,08(63,5 \%)$ dikategorikan tidak baik. Kemudian ditemukan bahwa tingkat kemampuan menembak pemain Tabing PSTS ke-21 dikategorikan cukup dengan perolehan rata-rata $=10,5(70,1 \%)$

Dengan demikian dapat disimpulkan bahwa tingkat kemampuan menembak pemain Tabing PSTS ke21 dikategorikan cukup.
\end{abstract}

Kata Kunci: Teknik, Teknik Dasar Sepak bola,

\begin{abstract}
Analysis of the Basic Techniques of Padang's PSTS Tabing Football Players The purpose of this study was to determine the level of technical ability to shoot PSTS Tabing players so that the results of the training were more specific to the mastery of shooting techniques. This research was carried out at PSTS Tabing.

The population in this study was conducted on 123 PSTS Tabing players, while the sampling technique was conducted by purposive sampling, namely 21 people as many as 25 people, direct data collection at PSTS Tabing field and in its implementation assisted by three judgment people who had coaching licenses.

Analysis of this research data using percentage technique (frequency distribution) that is. From the analysis of data U-21 obtained the initial phase, namely the mean $=9.2(76.67 \%)$ categorized as sufficient, the implementation phase is the mean $=17.24(71.83 \%)$ categorized as sufficient, and the final phase is the mean $=5.08(63.5 \%)$ categorized as not good. Then it was found that the level of shooting ability of the 21st PSTS Tabing player was categorized enough with the mean acquisition = $10.5(70.1 \%)$
\end{abstract}


Thus it can be concluded that the level of shooting capability of the 21st PSTS Tabing player is categorized as sufficient

Keywords: one or more word(s) or phrase(s), that it's important, spesific, or representative for the article

\section{PENDAHULUAN}

Olahraga merupakan bagian yang integral dari warisan kebudayaan manusia, hal ini digemari oleh banyak orang baik sebagai pelaku maupun sebagai penggemar. Dengan melakukan olahraga akan dapat membantu pertumbuhan badan, dan perkembangan pribadi untuk mengatasi ketegangan yang dialami serta memahami nilai-nilai kehidupan manusia yang sangat berharga.

Berkaitan dengan hal ini, pemerintah telah menggariskan dalam UU No. 3 tahun 2005 pasal 1 ayat 4 menyebutkan bahwa "olahraga adalah segala kegiatan yang sistematis mendorong, membina serta mengembangkan potensi jasmani, rohani dan sosial. Lebih lengkap dalam pasal 4 menyebutkan tujuan keolahragaan nasional yaitu; Keolahragaan nasional bertujuan memelihara dan meningkatkan kesehatan dan kebugaran prestasi, kualitas manusia, menanamkan nilai moral dan akhlak mulia, sportivitas, disiplin, mempererat dan membina persatuan dan kesatuan bangsa, memperkukuh ketahanan nasional, serta mengangkat harkat, martabat, dan kehormatan bangsa.

Keolahragaan nasional bertujuan memelihara dan meningkatkan kesehatan dan kebugaran prestasi, kualitas manusia, menanamkan nilai moral dan akhlak mulia, sportivitas, disiplin, mempererat dan membina persatuan dan kesatuan bangsa, memperkukuh ketahanan nasional, serta mengangkat harkat, martabat, dan kehormatan bangsa. Olahraga sepakbola adalah suatu cabang olahraga sangat popular di dunia. Sepakbola telah banyak mengalami perubahan dan perkembangan dari bentuk sederhana dan primitive sampai menjadi sepakbola modern yang sangat digemari dan disegani banyak orang baik anak-anak, dewasa, tua bahkan wanita. Kemajuan ilmu pengetahuan dan teknologi yang sangat pesat juga mempengaruhi perkembangan permainan sepakbola ini.

Perkembangan sepakbola di Sumatera Barat sangat pesat terutama Kota Padang. Hal ini terbukti dari banyaknya klub-klub dikota Padang yang melakukan pembinaan yang teratur, terarah, dan kontinue diantaranya PSTS Tabing, PSTS Tabing, PSPU Sumbar, PS GAUNG, PS PORSEP SEMEN PADANG, dan PS UNP. Selain itu juga diwarnai dengan bertambah banyak berdiri sekolah-sekolah sepakbola di kota Padang yang diharapkan melahirkan pemain yang berkualitas untuk mengangkat persepakbolaan Padang pada umumnya seperti SSB PSTS Tabing, SSB PSTS Tabing, SSB Padang Yunior, SSB Balai Baru, dan lain-lain serta yang membanggakan adalah ikut sertanya kesebelasan PSP Padang, dan Semen Padang pada divisi utama dan Liga Super Indonesia.

Disisi lain, olahraga sepakbola merupakan salah satu cabang olahraga permainan yang sangat populer oleh seluruh lapisan masyarakat baik kalangan bawah, kalangan menengah, dan kalangan atas. Baik tua maupun muda, dan dari kota-kota sampai ke daerah-daerah pelosok. Jika ditinjau dari perkembangannya, sepakbola dari tahun ke tahun selalu berkembang dengan pesat dan semakin menurut kemampuan yang sangat sempurna dari seorang pemain sepakbola. Dalam sepak bola 
seorang pemain harus menguasai teknik dasar untuk dapat bermain. Darwis (1999:9) yang mengemukakan bahwa: "Teknik dasar dalam sepakbola dikelompokkan atas dua teknik, yaitu teknik dengan bola terdiri dari menendang, menggiring, menyundul, melempar bola dengan teknik penjaga gawang, sedangkan teknik tanpa bola yaitu lari, lompat, tackling, teknik penjaga gawang".

Berdasarkan hal di atas, jelas teknik sangat dibutuhkan dalam suatu permainan sepakbola. Maka dari itu, teknik harus dilatih agar dapat mencapai prestasi yang tinggi. Lebih jauh Djezed (1985:1) mengungkapkan "salah satu faktor penting dalam permainan sepak bola yang dibutuhkan dan akan tetap dibutuhkan serta diperlukan sepanjang masa adalah dasar-dasar permainan sepakbola karena tanpa mengetahui dan memahami dasar-dasar permainan segala teknik dasar tidak mungkin seseorang mencapai prestasi terbaik.

Shooting merupakan salah satu teknik dasar yang harus dimiliki seorang pemain dalam permainan sepakbola. Kegunaan dari shooting ini yaitu untuk melakukan umpan dengan jarak jauh yang berguna dalam penyusunan serangan dan menciptakan peluang terciptanya gol dalam suatu pertandingan. Bila kemampuan shooting yang bagus sudah dimiliki maka kesempatan untuk memenangkan pertandingan akan semakin besar. Persatuan Sepakbola Tabing pembinaannya sudah cukup baik dan telah melalui prosedur latihan yang terprogram dan terencana. Namun, disamping itu, masih saja banyak kelemahan-kelemahan saat melakukan permainan terutama yang menyangkut teknik dasar sepakbola seperti shooting. Sering didapat kesalahan-kesalahan seperti tidak tepatnya sasaran dalam melakukan shooting, sehingga gagalnya tercipta gol.

Pada dasarnya setiap pemain diharapkan memiliki kemampuan untuk melakukan shooting dengan baik, karena bagi seorang pemain, olahraga merupakan ajang untuk berkompetisi dalam meraih prestasi olahraga yang setinggi-tingginya. Prestasi itu sebagai hasil tertinggi yang dicapai dengan proses panjang yang memiliki tujuan dan target tertentu. Untuk meraih tujuan tersebut diperlukan usaha melalui perencanaan dan pelaksanaan yang terarah, terkoordinir dengan penyediaan sarana dan prasarana yang memadai.

Tidak meningkatnya prestasi PSTS Tabing sekarang ini mungkin salah satu penyebabnya adalah karena sering mengabaikan unsur-unsur dasar yang dapat mendukung kemampuan pemain seperti kondisi fisik dan teknik, terutama pada ketepatanpara pemain sepakbola PSTS Tabing dalam melakukan Shooting. Dari sekian banyak teknik dalam permaian sepakbola, Shooting merupakan salah satu teknik dasar yang harus dimiliki oleh seorang pemain sepakbola yang berguna dalam peluang terciptanya gol dalam suatu pertandingan. Bila shooting yang bagus sudah dimiliki maka kesempatan untuk memenangkan pertandingan akan semakin besar.

Bertitik tolak dari kenyataan yang ada, penulis mencoba sejauh mana faktor-faktor kendala yang mempengaruhi ketidak sempurnaan waktu melaksanakan teknik dasar Shooting dalam sepakbola. Analisa teknik dasar Shooting sepakbola berguna bagi pelatih sepakbola dan pemain. Terutama objek penelitian ini berguna untuk menganalisis kesempurnaan gerakan khususnya pada pemain PSTS Tabing Padang.

\section{METODE}

Jenis penelitian yang dilakukan adalah survey terhadap teknik Shotting melalui observasi atau pengamatan langsung. Penelitian ini bertujuan untuk mengetahui tingkat kemampuan teknik Shotting pemain PSTS Tabing, maka penelitian ini menggunakan metode deskriptif. Mardialis (1989:26), 
mendefinisikan bahwa: "penelitian deskriptif adalah penelitian yang bertujuan mendeskripsikan apa yang saat ini sedang berlaku, dalam bentuk informasi-informasi mengenai keadaan-keadaan saat ini dan melihat keterkaitan antara variabel-variabel yang ada".

Penelitian ini termasuk jenis penelitian deskriptif yaitu penelitian yang bertujuan untuk membuat deskripsi, gambaran atau lukisan secara sitematis, faktual dan akurat mengenai fakta-fakta, serta sifat-sifat serta hubungan antar fenomena yang diselidiki. Berdasarkan dengan uraian di atas maka penelitian ini bertujuan untuk mendeskripsikan bagaimana analisis teknik Shotting pemain PSTS Tabing yang selanjutnya untuk kesempurnaan gerakan teknik sepakbola tersebut pada pemainPSTS Tabing.

\section{HASIL DAN PEMBAHASAN \\ Hasil Penelitian}

Dalam analisis shooting pemain sekolah sepakbola PSTS Tabing U-21. Kemudian dalam pengambilan data peneliti dibantu oleh tiga orang judgement dan seorang dewan dosen yang bertindak sebagai pengawas. Berdasarkan dari uraian diatas, maka yang akan dideskripsikan dalam penelitian ini adalah analisis shooting pemain PSTS Tabing U-21 yang terdiri dari fase awal, fase utama dan fase akhir (gerakan lanjutan).

\section{Fase awal (Fase Persiapan)}

Dari hasil pengukuran yang dilakukan terhadap sampel diperoleh skor tertinggi 12, skor terendah 5, dan jarak pengukuran (range) 7. Diperoleh nilai rerata hitung (mean) 9,2 dengan kriteria cukup dan tingkat pencapaian responden sebesar 76,67\%. nilai tengah (median) 10, nilai sering muncul (mode) 11, dan simpangan baku (standar deviasi) sebesar 1,94. Dapat dilihat pada tabel di halaman selanjutnya.

Tabel 3. Fase Awal (Persiapan) Analisis Shooting

\begin{tabular}{cccc}
\hline \multirow{2}{*}{ Rentang Norma } & Kriteria & \multicolumn{2}{c}{ Frekwensi } \\
& & Absolut & Relatif \\
\hline$>12.10$ & Sangat Baik & 0 & 0 \\
$10.17-12.10$ & Baik & 8 & 32 \\
$8.23-10.16$ & Cukup & 9 & 36 \\
$6.30-8.22$ & Kurang & 5 & 20 \\
$<6.30$ & Sangat Kurang & 3 & 12 \\
& Jumlah & 25 & 100 \\
\hline
\end{tabular}

Berdasarkan analisa data diperoleh hasil dari penelitian tiga orang judment terhadap 25 orang sampel pada fase awal yaitu tidak ada satu pun yang memiliki kreiteria sangat baik, sebanyak 8 orang (32\%) tergolong kategori baik, 9 orang (36\%) tergolong kategori cukup, 5 orang (20\%) tergolong kategori kurang dan 3 orang (12\%) tergolong kategori sangat kurang yang di miliki sampel. Untuk lebih jelasnya dapat dilihat dari histogram di bawah ini.

\section{Fase Utama (Tahap Pelaksanaan)}

Dari hasil pengukuran yang dilakukan terhadap sampel diperoleh skor tertinggi 22, skor terendah 13, dan jarak pengukuran (range) 9. Diperoleh nilai rerata hitung (mean) 17,24 
dengan kriteria cukup nilai pada tingkap pencapaian responden sebesar 71,83\%. Nilai tengah (median) 17, nilai sering muncul (mode) 20, dan simpangan baku (standar deviasi) sebesar 2,55 . Untuk lebih jelasnya distribusi data dapat dilihat pada tabel tabel dibawah ini.

Tabel 5. Fase Utama (Tahap Pelaksanaan) Analisis Shooting

\begin{tabular}{cccc}
\hline \multirow{2}{*}{ Rentang Norma } & Kriteria & \multicolumn{2}{c}{ Frekwensi } \\
& & Absolut & Relatif \\
\hline$>21.07$ & Sangat Baik & 1 & 4 \\
$18.52-21.07$ & Baik & 7 & 28 \\
$15.96-18.51$ & Cukup & 11 & 44 \\
$13.41-15.95$ & Kurang & 3 & 12 \\
$<13.41$ & Sangat Kurang & 3 & 12 \\
& Jumlah & 25 & 100 \\
\hline
\end{tabular}

Berdasarkan analisa data diperoleh hasil dari penelitian tiga orang judment terhadap 25 orang sampel pada fase utama sebanyak 1 orang (4\%) tergolong kategori sangat baik, 7 orang (28\%) tergolong kategori baik, 11 orang (44\%) tergolong kategori cukup, 3 orang (12\%) tergolong kategori kurang dan 3 orang (12\%) tergolong kategori sangat kurang yang di miliki sampel. Untuk lebih jelasnya dapat dilihat dari histogram di bawah ini.

\section{Fase Akhir (Gerakan Lanjutan)}

Dari hasil pengukuran yang dilakukan terhadap sampel diperoleh skor tertinggi 8, skor terendah 3, dan jarak pengukuran (range) 5. Diperoleh nilai rerata hitung (mean) 5,08 nilai tengah (median) 5, nilai sering muncul (mode) 4, dan simpangan baku (standar deviasi) sebesar 1,35. Untuk lebih jelasnya distribusi data dapat dilihat pada tabel tabel dibawah ini.

Tabel 6. Fase Akhir (Gerak Lanjutan) Analisis Shooting

\begin{tabular}{cccc}
\hline \multirow{2}{*}{ Rentang Norma } & Kriteria & \multicolumn{2}{c}{ Frekwensi } \\
& & Absolut & Relatif \\
\hline$>7.11$ & Sangat Baik & 1 & 4 \\
$5.76-7.11$ & Baik & 9 & 36 \\
$4.40-5.75$ & Cukup & 4 & 16 \\
$3.05-4.39$ & Kurang & 9 & 36 \\
$3.05<$ & Sangat Kurang & 2 & 8 \\
& Jumlah & 25 & 100 \\
\hline
\end{tabular}

Berdasarkan analisa data diperoleh hasil dari penelitian tiga orang judment terhadap 25 orang sampel pada fase akhir sebanyak 1 orang (4\%) tergolong kategori sangat baik, 9 orang $(36 \%)$ tergolong kategori baik, 4 orang $(16 \%)$ tergolong kategori cukup, 9 orang (36\%) 
Sport Science: Jurnal Sain Olahraga dan Pendidikan Jasmani ISSN 114-562X (Cetak), ISSN XXXX-XXXX(Online)

http://sportscience.ppj.unp.ac.id/index.php/jss/index

tergolong kategori kurang dan 2 orang (8\%) tergolong kategori sangat kurang yang di miliki sampel. Untuk lebih jelasnya dapat dilihat dari histogram pada halaman berikutnya

\section{Pembahasan}

Berdasarkan hasil analisis data terhadap analisi kemampuan shooting pemain PSTS Tabing yang dinilai oleh tiga orang judgement terhadap 25 orang sampel. Menurut Tim sepakbola FIK UNP (2003) "shooting adalah usaha untuk memasukan bola ke gawang dengan kaki atau bagian kaki." Keberhasilan seorang pemain mencetak gol tergantung terhadap beberpa faktor. Kemampuan melakukan shooting dengan kuat dan akurat dalam menggunakan kedua kaki adalah faktor yang paling penting.

Kualitas seperti antisipasi, kematapan, dan ketenangan di bawah tekanan lawan juga tak kalah pentingnya. Sasaran utama dari setiap serangan adalah untuk mencetak gol. Namun dalam kenyataan sebenarnya, pemain akan mencapai sasaran utama lebih sering dari pemain diduga karena untuk mencetak merupakan tugas yang paling sulit dalam sepakbola. Untuk mencetak gol pada gawang pemain harus mampu melakukan shooting di bawah tekanan pemainan dalam waktu yang terbatas, ruang yang terikat fisik yang lelah dan lawan yang agresif. Semua hal ini dilakukan dengan membuat suatu rangkaian shooting. Menurut Coerver (1985:153) menyatakan bahwa "setaip pemain harus mampu melakukan tembakan akurat baik secara dekat maupun jauh, karena mencetak gol merupakan bagian penting dalam sepakbola". Pendapat ini mengemukakan bahwa setiap pemain sepakbola harus mampu melakukan shooting dengan baik.

Senada dengan Luxbancher (2004:106) menyatakan bahwa "keberhasilan suatu shooting harus melewati beberapa fase yaitu fase persiapan, fase pelaksanaan, dan follow through." Ketiga fase ini harus dilewati dengan sempurna untuk mendapatka shooting yang baik sesuai dengan tujuan yang diinginkan. Sementara rata-rata tingkat kemampuan shooting pemain PSTS Tabing u-21 pada fase awal didapat mean $=9,2(76,67 \%)$. Ini menandakan bwha shooting pemain PSTS Tabing pada fase awal masih dalam katagori cukup.

Dan kemampuan shooting pemain PSTS Tabing pada fase utama didapat maean $=17,24$ (71,83\%). Ini menunjukan bahwa kemampuan shooting pemain PSTS Tabing pada fase utama masih dalam kategori cukup. Sedangkan kamampuan shooting pemain PSTS Tabing pada fase akhir didapat mean $=5,08(63,5 \%)$. Ini menunjukan bahwa kemampuan shooting pemain PSTS Tabing pada fase akhir masih dalam kategori kurang baik. Dari ketiga fase tersebut maka didapatkan kemampuan shooting pemain PSTS Tabing dengan mean $=10,5$ (70,1\%). Ini menunjukan bahwa shooting pemain PSTS Tabing dikatagorikan cukup. Artinya shooting yang dimiliki oleh 25 sampel dalam penelitian belum mencapai tingkat kemampuan yang atau shooting pemain PSTS Tabing berkisar antara menengah ke bawah.

Rendahnya kemampuan shooting yang dimiliki pemain PSTS Tabing diduga disebabkan kurangnya pengetahuan tentang shooting. Ini terlihat dari pelaksanaan shooting yang sering melakukan kesalahan-kesalahan. Selain itu yang menyebabkan rendahnya shooting karena keterbatasan sarana yang dimiliki pemain untuk latihan shooting karena keterbatasan sarana yang 
dimiliki seperti bola. Dan waktu yang dimiliki juga terbatas karena masih banyak teknik dasar sepakbola yang harus dikuasai pemain sementara frekuensi latihan hanya tiga kali dalam satu minggu.

Jika hal ini terus dibiarkan maka dikhawatirkan sekolah sepakbola PSTS Tabing akan sulit meraih kemenangan dalam setiap pertandingan yang dihadapi bahkan prestasi pemain PSTS Tabing akan menurun. Untuk itu para pemain harus mampu memusatkan perhatian pada posisi kaki tumpu, dan kaki yang akan menendang, posisi bahu dan pinggul dalam kaitannya dengan gawang, posisi lutut yang menendang dalam kaitannya dengan bola, dan gerakan akhir. Pada setiap latihan pelatih dan pemain harus mampu mengidentifikasi kekurangan dalam melaksanakan shooting.

Setelah pemain mampu melaksanakan berbagai keterampilan shooting dalam situasi latihan dengan tekanan sedikit, kemudian pemain harus mampu meningkatka keterampilan shooting dalam situasi permainan yang menekan akan ruang, waktu yang terbatas, fisik yang lelah dan lawan menghadap yang ketat. Semua itu harus sudah ada dalam program latihan sekolah sepakbola PSTS Tabing. Selain itu perkembangan individu pemain harus banyak melakukan latihan shooting diluar waktu yang telah ditetapkan di sekolah sepakbola PSTS Tabing.

\section{KESIMPULAN}

Berdasarkan hasil penelitian dapat ditarik kesimpulan yaitu: tingkat kemampuan shootingpemain PSTS Tabing u-21 dikategorikan cukup dengan perolehan mean $=10,5$ (70,1\%). Hal ini ditandai dengan perolehan fase awal mean $=9,2$ (76,67\%) dikategorikan cukup, fase utama dengan perolehan mean $=17,24(71,83 \%)$ diktegorikan cukup, dan fase akhir dengan perolehan mean $=5,08$ $(63,5 \%)$ dikategorikan kurang baik. Berdasarkan kesimpulan di atas penulis menyarankan agar Pelatih dan pemain harus dapat memperbaiki fase awal shooting pemain PSTS Tabing yang masih tergolong kurang.

Pelatih dan pemain agar dapat meningkatkan fase pelaksanaan dan fase akhir shooting agar menjadi lebih baik melalui latihan yang terpogram. Bagi pembina, pelatih dan pemain harus dapat mningkatkan kemampuan shooting pemain yang ada sekarang menjadi lebih baik. Bagi pelatih yang ingin meneliti lebih lanjut dapat menggunakan skipsi sebagai informasi.

\section{DAFTAR RUJUKAN}

Arikunto, Suharsimi. (2002).(1998). Prosedur Penelitian (Edisi V). Jakarta: Rineka Cipta.

Batty, Eric C, (2005). LatihanMetode Baru Sepakbola Penyerangan. Bandung: Pionir Jaya.

Coever. 1985. Sepakbola Program Pembinaan Pemain Ideal. Jakarta: PT. Gramedia

Djezed. 1985. Buku Pelajaran Sepakbola. Padang. FPOK IKIP

Darwis. 1999. Buku Pelajaran Sepakbola. Padang. FPOK IKIP 
Sport Science: Jurnal Sain Olahraga dan Pendidikan Jasmani ISSN 114-562X (Cetak), ISSN XXXX-XXXX(Online)

http://sportscience.ppj.unp.ac.id/index.php/jss/index

FIFA. (2008). Laws Of The Game Fifa. Jakarta: PSSI.

http/www.docstoc.com//docs//2878779/Analisis Teknik Dasar Sepakbola.

Kiram, Yanuar. 1999. Belajar Motorik. Padang: FIK UNP

Luxbacher, Joseph A. (2004). Sepakbola. Jakarta: Raja Grafindo Persada. 